\title{
Smoking and non-neoplastic lung disease in Canadian men and women
}

\author{
Mary Jane Ashley MD DPH MSc FRCPC, Bernard CK Choi MSc PhD, Anita WP Pak PhD \\ Ontario Tobacco Research Unit, Centre for Health Promotion and Department of Public Health \\ Sciences, University of Toronto, Toronto, Ontario; Bureau of Cardio-Respiratory Diseases and \\ Diabetes, Laboratory Centre for Disease Control, Health Canada, Ottawa, Ontario; Department \\ of Psychology, Brock University, St Catharines, Ontario
}

\begin{abstract}
MJ Ashley, BCK Choi, AWP Pak. Smoking and nonneoplastic lung disease in Canadian men and women. Can Respir J 1997;4(6):311-317.
\end{abstract}

MAIN OBJECTIVE: To document and assess the current health impact of non-neoplastic lung disease (NNLD) in Canadian men and women that is attributable to smoking. DESIGN: Comparison of three recent studies providing estimates of smoking-attributable deaths, potential years of life lost, hospital separations and hospital days due to NNLD in Canada. Review of recent epidemiological studies providing relative risk estimates of smoking-attributable mortality and morbidity for chronic obstructive pulmonary disease and pneumonia, including a meta-analysis.

MAIN RESULTS: Each year at least 6700 Canadian men and women die from NNLD attributable to smoking. Smoking-attributable NNLD deaths in men outnumber those in women by about 2 to 1 . The majority of these deaths are due to chronic obstructive pulmonary disease, which is exceeded in importance as a smoking-attributable cause of death only by lung cancer and ischemic heart disease. NNLD accounts for about $20 \%$ of all smokingattributable deaths in Canada, $14 \%$ of the potential years of life lost due to smoking, and $22 \%$ and $25 \%$ of all smokingattributable hospital separations and hospital days, respectively. Long term follow-up assessments of large cohorts suggest that the impact of smoking on health has been underestimated. Recent studies also suggest that women may be more susceptible than men to the adverse effects of smoking on lung function.

CONCLUSION: NNLD caused by smoking has an important health impact in Canada. Tobacco control strategies must be enhanced.

Key Words: Lung diseases, Morbidity, Mortality, Smoking

\section{Le tabagisme et la maladie pulmonaire non cancéreuse chez les Canadiens et Canadiennes}

OBJECTIF PRINCIPAL : Documenter et évaluer les influences actuelles sur la santé de la maladie pulmonaire non cancéreuse chez des Canadiens et Canadiennes, et qui sont imputables au tabagisme.

MODÈLE : Comparaison de trois études récentes fournissant des estimés des décès attribuables au tabagisme, des années potentielles de vie perdues, des congés donnés aux patients hospitalisés et des journées d'hospitalisation dus à la maladie pulmonaire non cancéreuse au Canada. Revue des études épidémiologiques récentes fournissant des estimés du risque relatif de la mortalité attribuable au tabagisme et de la morbidité liée à la maladie pulmonaire obstructive chronique et à la pneumonie, incluant une méta-analyse.

voir page suivante 
PRINCIPAUX RÉSULTATS : Chaque année au moins 6700 Canadiens et Canadiennes meurent d'une maladie pulmonaire non cancéreuse attribuable au tabagisme, ce qui représente environ 20 $\%$ de tous les décès attribuables au tabagisme. Chez les hommes, le nombre des décès dus à une maladie pulmonaire non cancéreuse attribuable au tabagisme dépasse celui des femmes dans une proportion de 2 hommes pour une femme. La majorité de ces décès est due à la maladie pulmonaire obstructive chronique qui est dépassée en importance comme cause de maladie attribuable au tabagisme seulement par le cancer du poumon et la maladie cardiaque ischémique. La maladie pulmonaire non cancéreuse attribuable au tabagisme représente environ $20 \%$ de tous les décès attribuables au tabagisme au Canada, $14 \%$ des années potentielles de vie perdues dues au tabagisme, et, respectivement, $22 \%$ pour l'ensemble des congés donnés aux patients hospitalisés pour une cause liée au tabagisme et $25 \%$ pour les journées d'hospitalisation. Les évaluations de suivi à long terme de grandes cohortes laissent croire que l'impact du tabagisme sur la santé a été sous-estimé. Des études récentes laissent croire que les femmes seraient plus susceptibles que les hommes aux effets indésirables du tabagisme sur la fonction pulmonaire.

CONCLUSION : La maladie pulmonaire non cancéreuse causée par le tabagisme a des influences importantes sur la santé au Canada. It faut promouvoir des approches pour lutter contre le tabagisme.
$\mathbf{I}^{\mathrm{t}}$ is now well established that smoking is the most important preventable cause of premature mortality and morbidity in Canadian men and women $(1,2)$, as it is in the populations of other developed countries $(3,4)$. At least 33,000 Canadians die each year as a result of tobacco use, which also accounts for more than 200,000 hospital separations, three million hospital days and some $\$ 9.5$ billion in costs from lost productivity and direct health care expenditures (2). Despite this enormous health toll, smoking remains prevalent. Estimates from the National Population Health Survey conducted in 1994 indicate that 6.9 million Canadians, 31\% of the population aged 15 years and over, smoke (5). Further, rates of smoking among young Canadians, after some years of decline, have now plateaued (6) and may actually be increasing in some provinces, notably in Ontario $(7,8)$.

The primary purpose of this paper is to document and assess current estimates of the health impact of smoking in Canada with regard to non-neoplastic lung disease (NNLD) and to point out some limitations of these data. As well, recent reports concerning long term epidemiological studies of the relationship of smoking to NNLD are reviewed, including a meta-analysis of relative risk estimates. Attention is drawn to recent studies that indicate the possibility that the lungs of women may be particularly susceptible to the adverse effects of tobacco smoke.

\section{HEALTH IMPACT OF SMOKING DUE TO NNLD}

Smoking-attributable mortality: Three studies provide estimates of the current mortality impact of tobacco use in Canadian men and women (Table 1). Peto et al (4), using relative risks of mortality derived from the American Cancer Society's second Cancer Prevention Study (9), estimated that in 1990 there were more than 39,600 smoking-attributable deaths in Canada, of which almost 6800 were from NNLD. These smoking-attributable NNLD deaths included $74 \%$ of all deaths from chronic obstructive pulmonary disease (COPD) and $13 \%$ of all deaths due to other respiratory causes, that is, $42 \%$ of all respiratory disease deaths in that year. These investigators also projected mortality due to smoking to the year 1995, and estimated that in that year among Canadians there would be 45,718 deaths from all causes due to smoking, of which 8258 would be coded to NNLD.

Makomaski Illing and Kaiserman (1), using risk estimates from the same source, concluded that in 1991 there were more than 8100 NNLD deaths among Canadians attributable to smoking, out of a total of 41,408 smoking-attributable deaths. Most recently, Single et al (2) used mortality estimates derived from a meta-analysis of epidemiological studies conducted by English et al (10), discussed further below. They concluded that in 1992 NNLD deaths in Canadians attributable to smoking exceeded 6700 , out of a total estimate of more than 33,000 smoking-attributable deaths.

In all three estimates shown in Table 1 and in the projected 1995 estimate of Peto et al (4), the vast majority of NNLD deaths were due to COPD (International Classification of Diseases, ninth revision [ICD-9] codes 490 to 496). In the context of smoking-attributable mortality in 1992, the number of COPD deaths (5815 deaths) was exceeded only by deaths from lung cancer $(11,805)$ and ischemic heart disease (6762) (2). Also, in the three estimates shown in Table 1, smoking-attributable deaths from NNLD in men outnumbered those in women by about 2 to 1 . However, in the projected estimate of Peto et al (4) for 1995, the corresponding ratio was $1.5: 1$. In all four estimates NNLD accounted for $17 \%$ to $20 \%$ of all deaths attributable to smoking among $\mathrm{Ca}-$ nadians.

Premature mortality: Peto et al (4) estimated that $23 \%$ and $25 \%$ of smoking-attributable NNLD deaths in Canadian men and women, respectively, occurred before the age of 70 , but they did not provide estimates of potential years of life lost (PYLL). Makomaski Illing and Kaiserman (1), however, estimated PYLL both before age 65 and age 75 years (Table 2). More than 20,000 PYLL occur before the age of 75 years from NNLD attributable to smoking, with the loss being twice as great in men as in women. However, NNLD accounted for only $4 \%$ and $8 \%$ of all smoking-attributable PYLL before ages 65 and 75 years, respectively. Single et al (2) estimated that almost 71,000 years of life are lost from NNLD when men and women of all ages are considered, $14 \%$ of all smoking-attributable PYLL. Deaths in men accounted for $62 \%$ of this loss.

Hospital morbidity: Estimates of hospital separations (hospital discharges or deaths among in-patients) and hospital days indicate that NNLD accounted for $22 \%$ and $25 \%$ of all smoking-attributable hospital separations and hospital days, respectively, in 1992 (Table 3). In all, about 46,000 hospital separations and more than 757,000 hospital days were due to NNLD caused by smoking.

Comparability of the mortality estimates: Because the 
TABLE 1

Smoking-attributable deaths from non-neoplastic lung disease (NNLD) and all causes, Canadian men and women 1990, 1991 and 1992

\begin{tabular}{|c|c|c|c|}
\hline Cause of death* & Men & Women & Total \\
\hline \multicolumn{4}{|l|}{1990 - Peto et al (4) } \\
\hline Chronic obstructive pulmonary disease (490 to 496 ) & 3848 & 1864 & 5712 \\
\hline Other respiratory (rest of 460 to 519 ) & 684 & 386 & 1070 \\
\hline Smoking-attributable NNLD & 4532 & 2250 & 6782 \\
\hline All smoking-attributable & 27,582 & 12,073 & 39,655 \\
\hline \multicolumn{4}{|l|}{1991 - Makomaski Illing and Kaiserman (1) } \\
\hline Bronchitis/emphysema (491 to 492 ) & 962 & 376 & 1338 \\
\hline Chronic airway obstruction (496) & 3252 & 1531 & 4783 \\
\hline Asthma (493) & 61 & 65 & 126 \\
\hline Pneumonia/influenza (480-487) & 912 & 966 & 1878 \\
\hline Smoking-attributable NNLD & 5187 & 2838 & 8125 \\
\hline All smoking-attributable & 27,867 & 13,541 & 41,408 \\
\hline \multicolumn{4}{|l|}{1992 - Single et al (2) } \\
\hline Chronic obstructive pulmonary disease ( 490 to 492,496$)$ & 3998 & 1817 & 5815 \\
\hline Pneumonia/influenza (480 to 487 ) & 608 & 322 & 930 \\
\hline Smoking-attributable NNLD & 4606 & 2139 & 6745 \\
\hline All smoking-attributable & 23,018 & 10,480 & 33,498 \\
\hline
\end{tabular}

*Numbers in parentheses are International Classification of Diseases, 9th revision codes

TABLE 2

Smoking-attributable potential years of life lost (PYLL) from non-neoplastic lung disease (NNLD) and all causes in Canadian men and women - 1991 and 1992

\begin{tabular}{|c|c|c|c|}
\hline Cause of death* & Men & Women & Tota \\
\hline \multicolumn{4}{|c|}{ PYLL before age 65, 1991 - Makomaski Illing and Kaiserman (1) } \\
\hline Bronchitis/emphysema (491 to 492 ) & 390 & 1864 & 574 \\
\hline Asthma (493) & 0 & 64 & 64 \\
\hline Pneumonia/influenza (480 to 487 ) & 345 & 421 & 766 \\
\hline Chronic airways obstruction (496) & 1268 & 716 & 1984 \\
\hline Smoking-attributable NNLD & 2003 & 1385 & 3388 \\
\hline All smoking-attributable & 66,380 & 28,648 & 95,028 \\
\hline \multicolumn{4}{|c|}{ PYLL before age 75, 1991 - Makomaski Illing and Kaiserman (1) } \\
\hline Bronchitis/emphysema (491 to 492) & 2987 & 1269 & 4256 \\
\hline Asthma (493) & 25 & 147 & 172 \\
\hline Pneumonia/influenza (480 to 487 ) & 2281 & 1309 & 3590 \\
\hline Chronic airways obstruction (496) & 8459 & 4076 & 12,535 \\
\hline Smoking-attributable NNLD & 13,752 & 6801 & 20,553 \\
\hline All smoking-attributable & 186,442 & 75,586 & 262,028 \\
\hline \multicolumn{4}{|c|}{ PYLL for all ages, 1992 - Single et al (2) } \\
\hline Bronchitis/emphysema (491 to 492) & 38,377 & 23,237 & 61,614 \\
\hline Pneumonia/influenza (480 to 487 ) & 5677 & 3562 & 9240 \\
\hline Smoking-attributable NNLD & 44,054 & 26,799 & 70,854 \\
\hline All smoking-attributable & 318,960 & 176,679 & 495,640 \\
\hline
\end{tabular}

${ }^{*}$ Numbers in parentheses are International Classification of Diseases, 9th revision codes

three studies reported estimates based on deaths in three consecutive years - 1990, 1991 and 1992 - some differences in the estimates of smoking-attributable NNLD mortality would be expected. Also, as shown in Table 1, the ICD rubrics used in deriving the mortality estimates were not consistent across the studies. Makomaski Illing and Kaiserman (1) and Single et al (2) used essentially the same rubrics (ICD-9 491, 492, 496, 480 to 487), except that the former included ICD-9 493, while the latter included ICD-9 490. However, in 1994 only 454 and 153 deaths in Canada were ascribed to these codes, respectively, so that the inclusion or exclusion of these codes made little difference to the resulting estimates. Rather, the difference in the estimates of smoking-attributable mortality obtained by Makomaski Illing and Kaiserman (1) and Single et al (2) was due primarily to the different relative risk estimates that were used, described above. In contrast, Peto et al (4) used a wider range of ICD codes, which, in 1994 in Canada, accounted for 18,342 deaths, whereas the codes used by Makomaski Illing and Kaiserman (1) and Single et al (2) accounted for 15,922 and 


\section{TABLE 3}

Smoking-attributable morbidity from non-neoplastic lung disease (NNLD) and all causes, Canadian men and women 1992

\begin{tabular}{|c|c|c|c|}
\hline Cause* $^{*}$ & Men & Women & Total \\
\hline \multicolumn{4}{|l|}{ Hospital separations, 1992 - Single et al (2) } \\
\hline Chronic obstructive pulmonary disease $(490$ to 492,496$)$ & 22,595 & 14,277 & 36,872 \\
\hline Pneumonia/influenza (480 to 487 ) & 5709 & 3487 & 9196 \\
\hline All smoking-attributable & 130,724 & 77,371 & 208,095 \\
\hline \multicolumn{4}{|l|}{ Hospital days, 1992 - Single et al (2) } \\
\hline Smoking-attributable NNLD & 459,596 & 297,980 & 757,576 \\
\hline All smoking-attributable & $1,833,024$ & $1,191,241$ & $3,024,265$ \\
\hline
\end{tabular}

${ }^{*}$ Numbers in parentheses are International Classification of Diseases, 9th revision codes

TABLE 4

Relative risk (RR) estimates for chronic obstructive pulmonary disease and pneumonia in exsmokers and current smokers by amount smoked compared with never smokers

\begin{tabular}{|c|c|c|c|c|c|c|}
\hline \multirow[b]{2}{*}{ Source } & \multirow{2}{*}{$\begin{array}{c}\text { Number of } \\
\text { studies }\end{array}$} & \multirow[b]{2}{*}{ Sex } & \multicolumn{2}{|c|}{ Exsmokers } & \multicolumn{2}{|c|}{ Current smokers } \\
\hline & & & $\mathbf{R R}$ & $95 \% \mathrm{Cl}$ & $\mathbf{R R}$ & $95 \% \mathrm{Cl}$ \\
\hline \multicolumn{7}{|c|}{ Chronic obstructive pulmonary disease } \\
\hline English et al (10) & 5 & $\mathrm{M} / \mathrm{F}$ & 6.70 & 5.94 to 7.57 & 9.80 & 8.63 to 11.1 \\
\hline Doll et al (18) & 1 & M & 5.7 & na & 12.7 & na \\
\hline \multicolumn{7}{|l|}{ Pneumonia } \\
\hline English et al (10) & 4 & $\mathrm{M} / \mathrm{F}$ & 1.29 & 1.15 to 1.4 & 1.47 & 1.33 to 1.61 \\
\hline Doll et al (18) & 1 & $\mathrm{M}$ & 1.27 & na & 1.94 & na \\
\hline
\end{tabular}

F Female; M Male; NA not available

15,621 deaths, respectively. However, Peto et al (4) and Makomaski Illing and Kaiserman (1) both used the same relative risks estimates. Consequently, despite the wider range of codes included by Peto et al (4), the estimates of NNLD mortality attributable to smoking were fairly close. Regardless of the variability in the available estimates, the 'bottom line' is clear - smoking-attributable NNLD deaths among Canadians are substantial, accounting for between one-fifth and one-sixth of all smoking-attributable deaths.

\section{RISKS OF NNLD MORTALITY AND MORBIDITY ASSOCIATED WITH SMOKING}

Mortality: A study by Canadian investigators was among the first to document the excess risk of mortality from NNLD in smokers compared with nonsmokers $(11,12)$. In the final six-year follow-up study of some 78,000 male veterans, initiated in 1955 by the Department of National Health and Welfare (12), it was found that veterans with a lifetime history of smoking cigarettes had about 11 and eight times the risk of mortality from chronic bronchitis and emphysema, respectively, compared with nonsmokers. A dose-response relationship between the amount smoked daily and the risk of mortality was also observed. For pneumonia and influenza there was a small increase in relative risk (1.4). Since then, a host of epidemiological studies from many countries have confirmed the causal relationship between smoking and COPD in both men and women, as well as a small increase in the risk of mortality from pneumonia (13-17).
Doll et al (18) recently reported on a 40-year follow-up of mortality in relation to smoking in male British doctors. The annual death rate from COPD in current smokers was almost 13 times that experienced by men who had never smoked regularly, while among former smokers the rate was almost six times higher. A very strong relationship with amount smoked daily was found among current smokers. For pneumonia, a weak, but highly statistically significant relationship was observed, the annual death rate among current smokers being about twice that of men who had never smoked regularly. The authors noted that the increased risk of pneumonia was the same at all ages, possibly because of an increased risk associated with the presence of COPD.

Doll et al (18) concluded that their earlier 20-year followup (19), like other studies of that time, had substantially underestimated the hazards of long term tobacco use. Thun et al (20) compared the mortality outcomes of 200,000 smokers and 480,000 lifelong nonsmokers in the two large American Cancer Society prospective studies, one dealing with the years 1959 to 1965 and the other with the years 1982 to 1986, and reached a similar conclusion. They found that among men, the mortality ratio of smokers compared with nonsmokers for COPD increased between the first and second study from 9.3 (95\% CI 6.6 to 12.9 ) to 11.7 (95\% CI 9.1 to 15.0 ), while the corresponding figures for women were 6.7 (95\% CI 4.4 to 10.2 ) and 12.8 (95\% CI 10.4 to 15.9). The results reflected the changing patterns of cigarette smoking in men 
and women over this century, in particular the increasing convergence of smoking rates between the sexes.

Morbidity: Many epidemiological studies of respiratory symptoms and lung function in adult populations, including some conducted in Canada, have demonstrated the adverse effects of smoking in the respiratory health of both men and women (13-17). For example, Manfreda et al (21), in a population-based prevalence study of residents in urban (Winnipeg) and rural (Portage la Prairie) communities of Manitoba conducted more than two decades ago, showed that both men and women who smoked experienced excess cough, phlegm, wheeze, breathlessness and reduced lung function. The adverse effects of smoking on the respiratory health of young people, including effects on respiratory symptoms, lung function and respiratory morbidity, have also been documented in numerous studies, as summarized and highlighted in a 1994 report from the United States Surgeon General (22).

Several studies published in this decade provide data indicating that women may be more susceptible to the detrimental effects of smoking on pulmonary function than men. Chen et al (23), in a population-based study of 1149 adults in a rural community in Saskatchewan, examined the interaction between sex and smoking habits on pulmonary function. They found that cigarette smoking was more detrimental to the lung function of women than to that of men. Specifically, in multivariate analyses it was shown that the regressions of forced expiratory volume in $1 \mathrm{~s}\left(\mathrm{FEV}_{1}\right)$ and maximum midexpiratory flow rate decreased, and that the regression of phase III of the single-breath nitrogen test ( $\Delta$ nitrogen/L) increased with increasing pack-years more rapidly in women than in men. Xu et al (24), in a multivariate analysis of sex differences in the effects of smoking on pulmonary function in adult men and women who participated in the Beijing Respiratory Health Study, also showed that the adverse effects of smoking on pulmonary function were greater in women than in men. Kanner et al (25) attributed the higher prevalence of airway hyperresponsiveness found in smoking women enrolled in the Lung Health Study to their smaller airway calibre in comparison with their male counterparts. Paoletti et al (26), in a study that took account of initial airway calibre in assessing the independent effects of age, sex and smoking on bronchial responsiveness, also showed that the airways of females were more susceptible to cigarette smoke than were those of males.

Recently, Gold et al (27), in a study of the effects of cigarette smoking on the level and rate of growth of pulmonary function in large cohorts of adolescent boys and girls, demonstrated that the growth of lung function in association with smoking was more severely affected in the girls. This finding is particularly worrisome in the context of the ages at which adolescent girls and boys begin to smoke. In the 1994 Canadian Youth Smoking Survey (6) it was found that although the rates of beginning to smoke were similar in boys and girls ages 10 to 12 years (4\% in each), by ages 13 to 14 years this rate was significantly higher than girls $(15 \%)$ compared with boys (9\%). Girls may not only be more susceptible to the ad- verse effects of smoking, but they appear to be getting a 'head start' on this addiction.

While sex differences in susceptibility to the smokinginduced changes in lung function require more study, particularly with regard to underlying biological mechanisms, the primal importance of smoking cessation in reducing the age-related decline in $\mathrm{FEV}_{1}$ in smokers with mild obstructive pulmonary disease is beyond dispute $(17,28-31)$. It has been demonstrated in a randomized clinical trial that an aggressive smoking intervention program significantly reduces the agerelated decline in $\mathrm{FEV}_{1}$ in middle-aged smokers with mild airway obstruction and that the effects of smoking cessation were much more important than those realized from bronchodilation therapy (32).

Combined risk estimates: As noted earlier, English et al (10) recently conducted a meta-analysis of relative risk estimates for a wide range of conditions associated with smoking. In a comprehensive review of the literature they identified three cohort studies and two case-control studies concerning COPD (in four of which mortality was the outcome measure), and four cohort studies (in three of which mortality was the outcome measure) concerning pneumonia that met predetermined criteria for inclusion. Their pooled risks for these conditions, shown in Table 4, are compared with the mortality estimates of Doll et al (18), which appeared subsequently. For COPD both estimates indicate a very strong relationship between smoking and COPD, an effect that persists in exsmokers. They concluded that the evidence of causality was 'sufficient', in that chance, confounding and other bias could be ruled out with reasonable confidence using well-established criteria such as statistical significance and power, time order, strength of association, specificity of effect and/or cause, consistency on replication, predictive performance, and theoretical, biological, factual and statistical coherence. For pneumonia the effect is much weaker, but as Doll et al (18) pointed out, it is of some importance because of the substantial number of deaths that are attributed to this cause. English et al (10) considered the evidence of causation to be "limited". Although an association has been found that was credible, chance, confounding or other bias could not be ruled out with reasonable confidence. By applying these relative risk fractions to the prevalence of smoking in the Australian population, they estimated that $82 \%$ and $76 \%$ of COPD in men and women, respectively, in that country, can be attributed to smoking. The corresponding estimates for pneumonia were $19 \%$ and $14 \%$. When these relative risks were applied to the prevalence of smoking in $\mathrm{Ca}$ nadian men and women, similar estimates were obtained (2).

\section{DISCUSSION}

These estimates of smoking-attributable mortality have limitations because the parameters measured are by no means comprehensive. The estimates, therefore, are considered to be conservative $(1,2,4)$. No account is taken, for example, of the direct health care impact of morbidity and disability not requiring hospitalization. Although life lost due to premature mortality was considered, composite measures 
of health impact, such as the sum of the years of life lost because of premature mortality and years of life lived with disability, adjusted for the severity of disability (DALYs), were not estimated. As well, with regard to NNLD specifically, the health impact of passive smoking was not considered. In children, a causal association has now been established between exposure to environmental tobacco smoke (ETS) and lower respiratory infections such as bronchitis and pneumonia; and between ETS and upper respiratory tract irritation. There is also a small but significant reduction in lung function, and additional episodes and increased severity of symptoms in children with asthma exposed to ETS (33). Further, the health impact of ETS exposure in children, in terms of mortality and morbidity, is by no means trivial. Based on a comprehensive review and meta-analysis of the literature, DiFranza and Lew (34) estimated that, in the United States each year, 136 to 212 deaths from lower respiratory tract illnesses, 529,000 physician visits for asthma, 1.3 to 2 million visits to physicians for coughs, and in children younger than 5 years of age, 260,000 to 436,000 episodes of bronchitis and 115,000 to 190,000 episodes of pneumonia were attributable to smoking by others. Among adults, including young adults, the adverse health effects of ETS exposure, including reduced lung function, increased cough and phlegm production, and chest discomfort, have also been documented (33,35-39), but estimates of the health impact are not available.

Despite these limitations, the evidence reviewed in this paper makes it clear that smoking-attributable NNLD in the Canadian population not only has a substantial health impact in its own right, but it also is an important component of overall smoking-attributable mortality and morbidity.

The importance of smoking as a preventable risk factor for a wide array of adverse health outcomes has been recently emphasized in this journal (40) and elsewhere (41). The urgency of addressing smoking in both clinical and public health contexts is evident. Clinicians play important roles in all aspects of the comprehensive tobacco control strategy that has been adopted in Canada (42), from counselling and other interventions in clinical settings to political advocacy (40). Their roles in the context of smoking cessation are well documented, and clinical practice guidelines have recently been published (43-45). Recent policy statements have also emphasized the role of physicians with regard to the protection of nonsmokers, in particular children, from the effects of ETS $(43,44,46)$ and the prevention of smoking in persons who have not started to smoke, mainly young people $(43,44$, 47). Programs to increase the effectiveness of Canadian physicians' actions are underway (48) and are being adopted in clinical practice (49). Nonetheless, recent unpublished survey data suggest that the actual practices of Canadian physicians in the contexts of prevention, protection and cessation are still far from ideal (personal communication). Barriers to the performance of clinical roles, including frustration about the efficacy of counselling, time constraints, unavailability of materials and procedures, and lack of training, were also identified (50, personal communication). As well, misunder- standing about the right to bill for clinical tobacco interventions may limit physician involvement. For example, only $32 \%$ of Canadian family physicians surveyed believed they could bill their health plans for providing smoking-cessation counselling to patients with no smoking-related illness, while, in fact, all provinces and territories except British Columbia and Alberta have billing codes for clinical tobacco interventions, which include counselling (50).

While there is some evidence that the tobacco-related epidemic of disease and death in Canada is beginning to plateau, at least among men ages 35 to 69 years (4), on a global level the full impact of the tobacco epidemic is still to be experienced. Evidence from the Global Burden of Disease Study (51) indicates that by the year 2020 tobacco will be the leading cause of DALYs, accounting for $9 \%$ of the total burden worldwide, as well as for 8.4 million deaths annually. It is imperative to enhance tobacco control strategies, not only in Canada, but worldwide.

ACKNOWLEDGEMENTS: Thanks to staff members of the Ontario Tobacco Research Unit at the University of Toronto, particularly to Pamela Bolan for conducting the literature search, Anita Sorrentino for retrieving articles used in this paper, Paola Greco for secretarial assistance and Marilyn Pope for proofreading. This work originated as part of a project entitled Tobacco and Women's Health, undertaken for Health Canada by the authors under the auspices of the Ontario Tobacco Research Unit. The financial support of Health Canada for this project is gratefully acknowledged.

\section{REFERENCES}

1. Makomaski Illing EM, Kaiserman MJ. Mortality attributable to tobacco use in Canada and its regions, 1991. Can J Public Health 1995;86:257-65.

2. Single E, Robson L, Xie X, et al. The Costs of Substance Abuse in Canada. Toronto: Canadian Centre on Substance Abuse, 1996.

3. McGinnis JM, Foege WH. Actual causes of death in the United States. JAMA 1993;270:2207-12.

4. Peto R, Lopez AD, Boreham J, Thun M, Health C Jr. Mortality from Smoking in Developed Countries 1950-2000: Indirect Estimates from National Vital Statistics. Oxford: Oxford University Press, 1994.

5. Statistics Canada. National Population Health Survey Overview 1994-95. Health Reports 1995:7:45-8.

6. Stephens T, Morin M, eds. Youth Smoking Survey 1994. Technical Report. Ottawa: Minister of Supply and Services, 1996.

7. Adlaf E, Ivis F, Smart R, Walsh G. The Ontario Student Drug Survey 1997-1995. Toronto: Addiction Research Foundation, 1995.

8. Ontario Tobacco Research Unit. Monitoring the Ontario Tobacco Strategy. Progress Toward Our Goals 1995/95. Toronto: Ontario Tobacco Research Unit, 1996.

9. Peto R, Lopez AD, Boreham J, Thun M, Heath C. Mortality from tobacco in developed countries: indirect estimation from national vital statistics. Lancet 1992;339:1268-78.

10. English DR, Holman CDJ, Milne E, et al. The Quantification of Drug Caused-Morbidity and Mortality in Australia, 1992. Canberra: Commonwealth Department of Human Services and Health, 1995.

11. Best EWR, Josie GH, Walker CB. A Canadian study of mortality in relation to smoking habits. A preliminary report. Can J Public Health 1961;52:99-106.

12. Department of National Health and Welfare. A Canadian Study of Smoking and Health. Final Report. Ottawa: Department of National Health and Welfare, 1966.

13. United States Department of Health Education and Welfare. Smoking and Health. A Report of the Surgeon General, 1979 [DHEW publication no (PHS) 79-50066]. Rockville: Public Health Service, Office of Smoking and Health.

14. United States Department of Health and Human Services. The Health Consequences of Smoking for Women. A Report of the Surgeon 
General, 1980. Rockville: Public Health Service, Office of Smoking and Health.

15. United States Department of Health and Human Services. The Health Consequences of Smoking: Chronic Obstructive Lung Disease. A Report of the Surgeon General, 1984 [DHHS publication no (PHS) 84-50205]. Rockville: Public Health Service, Office of Smoking and Health.

16. United States Department of Health and Human Services. Reducing the Health Consequences of Smoking: 25 Years of Progress. A Report of the Surgeon General, 1989. [DHHS publication no (CDC) 89-8411]. Rockville: Public Health Service, Office of Smoking and Health.

17. United States Department of Health and Human Services. The Health Benefits of Smoking Cessation. A Report of the Surgeon General, 1990 [DHHS publication no (CDC) 90-8416]. Rockville: Public Health Service, Office of Smoking and Health.

18. Doll R, Peto R, Wheatley K, Gray R, Sutherland I. Mortality in relation to smoking: 40 years' observations on male British doctors. BMJ 1994;309:901-11.

19. Doll R, Peto R. Mortality in relation to smoking: 20 years' observations of British doctors. BMJ 1976;ii:1525-36.

20. Thun MJ, Day-Lally CA, Calle EE, Flanders WD, Heath CW. Excess mortality among cigarette smokers: changes in a 20-year interval. Am J Public Health 1995:85:1223-30.

21. Manfreda J, Nelson N, Cherniack RM. Prevalence of respiratory abnormalities in a rural and an urban community. Am Rev Respir Dis 1978;117:215-226.

22. United States Department of Health and Human Services. Preventing Tobacco Use Among Young People. A Report of the Surgeon General, 1994. Washington: Public Health Service, Office of Smoking and Health, US Government Printing Office.

23. Chen Y, Horne SL, Dosman JA. Increased susceptibility to lung dysfunction in female smokers. Am Rev Respir Dis 1991;143:1224-30.

24. Xu X, Li B, Wang L. Gender differences in smoking effects on adult pulmonary function. Eur Respir J 1994;7:477-83.

25. Kanner RE, Connett JE, Altose MD, et al. Gender differences in airway hyperresponsiveness in smokers with mild COPD. The Lung Health Study. Am J Respir Crit Care Med 1994;150:956-61.

26. Paoletti P, Carrozzi L, Viegi G, et al. Distribution of bronchial responsiveness in a general population: Effect of sex, age, smoking and level of pulmonary function. Am J Respir Crit Care Med 1995;15:1770-7.

27. Gold DR, Wang X, Wypij D, Speizer FE, Ware JE, Dockery DW. Effects of cigarette smoking on lung function in adolescent boys and girls. N Engl J Med 1996;335:931-7.

28. Higgins MW, Enright PL, Kronmal RA, Schenker MB, Anton-Culver $\mathrm{H}$, Lyles M. Smoking and lung function in elderly men and women. The Cardiovascular Health Study. JAMA 1993;269:2741-8.

29. Burchfiel CM, Marcus EB, Curb JD, et al. Effects of smoking and smoking cessation on longitudinal decline in pulmonary function. Am J Respir Crit Care Med 1995;151:1778-85.

30. Sandvik L, Erikssen G, Thaulow E. Long term effects of smoking on physical fitness and lung function: A longitudinal study of 1,393 middle aged Norwegian men for seven years. BMJ 1995;311:715-8.

31. Burchfiel CM, Marcus EB, Sharp DS, et al. Characteristics associated with rapid decline in forced expiratory volume. Ann Epidemiol 1996;6:217-27.

32. Anthonisen NR, Connett JE, Kiley JP, et al. Effects of smoking intervention and the use of an inhaled anticholinergic bronchodilator on the rate of decline of FEV1. The Lung Health Study. JAMA 1994;272:1497-505.

33. United States Department of Health and Human Services. Respiratory Health Effects of Passive Smoking: Lung Cancer and Other Disorders. The Report of the US Environmental Protection Agency, National Institutes of Health, National Cancer Institute. Smoking and Tobacco Control Monograph 4 [NIH publication no 93-3605]. Bethesda: National Cancer Institiute of the NIH, 1993.

34. DiFranza JR, Lew RA. Morbidity and mortality in children associated with the use of tobacco products by other people. Pediatrics 1996;97:560-8.

35. Robbins AS, Abbey DE, Lebowitz MD. Passive smoking and chronic respiratory disease symptoms in non-smoking adults. Int J Epidemiol 1994;22:809-17.

36. Dale RE, Hill GB, Spitzer WO. Adult respiratory disease and environmental tobacco smoke. In: Hirsch A, Goldberg M, Martin JP, Masse R, eds. Prevention of Respiratory Diseases. New York: Marcel Decker, 1994:417-40.

37. Leuenberger P, Schwatz J, Ackermann-Liebrich U, et al. Passive smoking exposure in adults and chronic respiratory symptoms (SAPALDIA Study). Am J Respir Crit Care Med 1994;150:1222-8.

38. Cunningham J, O'Connor GT, Dockery DW, Speizer FE. Environmental tobacco smoke, wheezing, and asthma in children in 24 communities. Am J Respir Crit Care Med 1996;153:218-24.

39. Jaakkola MS, Jaakkola JJL, Becklake MR, Ernst P. Effect of passive smoking on the development of respiratory symptoms in young adults: An 8-year longitudinal study. J Clin Epidemiol 1996;49:581-6.

40. Joint Committee on Smoking and Health. Smoking and health: A physician responsibility. A statement of the Joint Committee on Smoking and Health. Can Respir J 1995; 2:150-4.

41. American Thoracic Society. Cigarette Smoking and Health. Am J Respir Care Med 1996;153:861-5.

42. Health Canada. Directions. The Directional Paper of the National Strategy to Reduce Tobacco Use. An Update: 1993. Ottawa: Health Canada.

43. Canadian Task Force on the Periodic Health Examination: Canadian Guide to Clinical Preventive Health Care [cat no H21-117/11994E]. Ottawa: Health Canada, 1994.

44. United States Preventive Services Task Force. Guide to Clinical Preventive Services, 2nd edn. Baltimore: Williams \& Wilkins, 1996:597-609.

45. The Smoking Cessation Clinical Practice Guideline Panel and Staff. The Agency for Health Care Policy and Research smoking cessation clinical practice guideline. JAMA 1996;275:1270-80.

46. Pattemore PK. The Paediatric Society of New Zealand: passive exposure of children to environmental tobacco smoke. NZ Med J 1995; 108:196-7.

47. Canadian Medical Association. Tobacco and health. CMA Policy Summary. Can Med Assoc J 1997;156:240A-C.

48. Canadian Council on Smoking and Health. Guide Your Patients to a Smoke-Free Future. Ottawa: Canadian Council on Smoking and Health, 1992.

49. Bass F. Mobilizing physicians to conduct clinical interventions in tobacco use through a medical-association program: 5 years' experience in British Columbia. Can Med Assoc J 1996;154:159-64.

50. Sullivan P, Kothari A. Right to bill may affect amount of tobacco counselling by MDs. Can Med Assoc J 1997;156:241-3.

51. Murray CJL, Lopez AD. Evidence-based health policy - lessons from the Global Burden of Disease Study. Science 1996;274:740-3. 


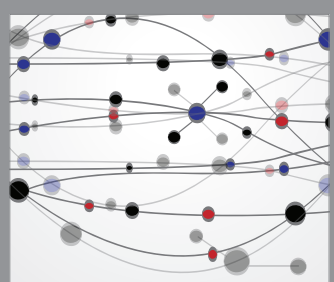

The Scientific World Journal
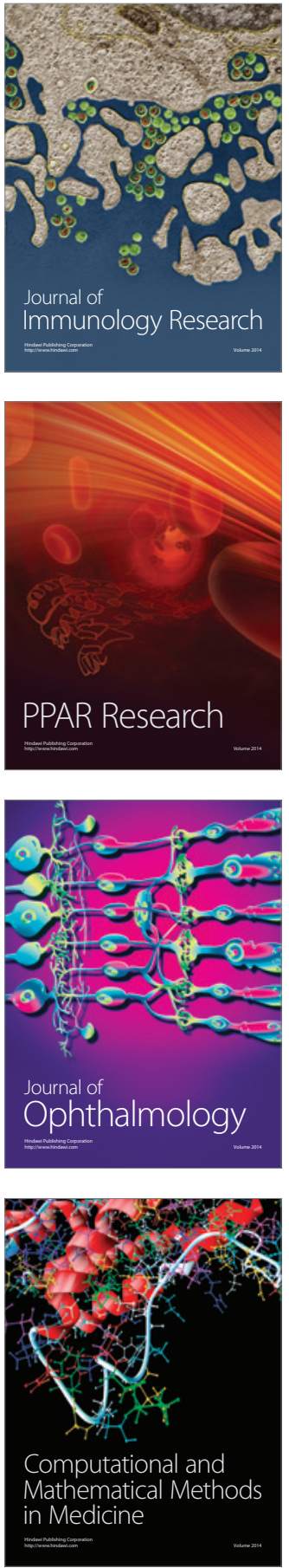

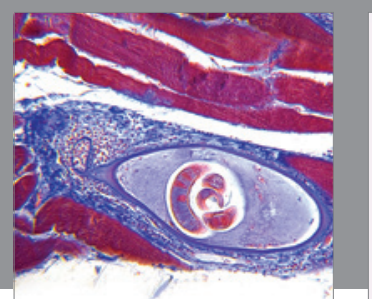

Gastroenterology Research and Practice

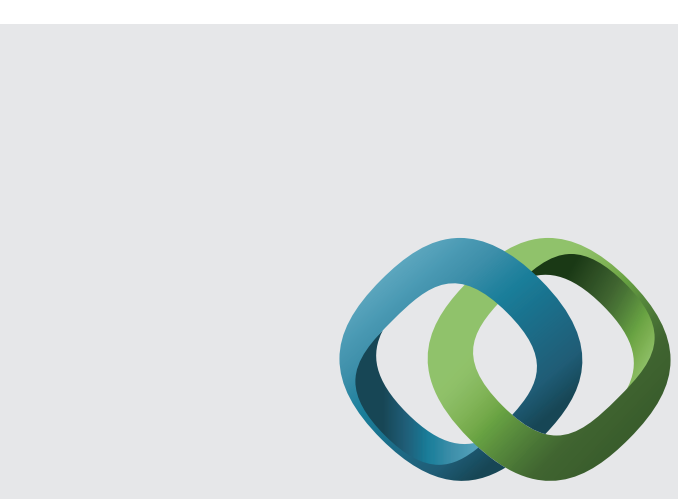

\section{Hindawi}

Submit your manuscripts at

http://www.hindawi.com
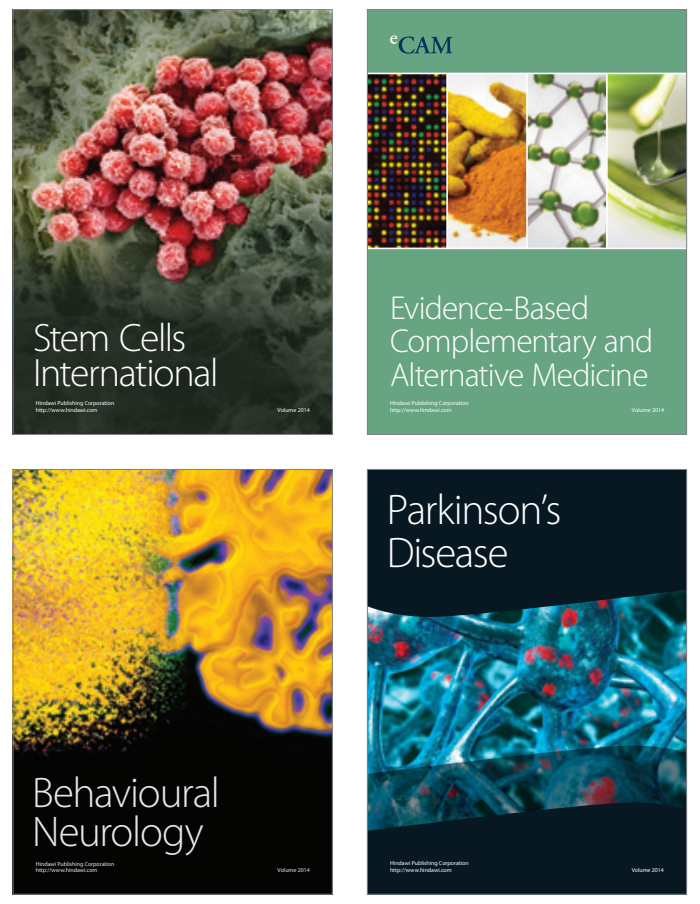
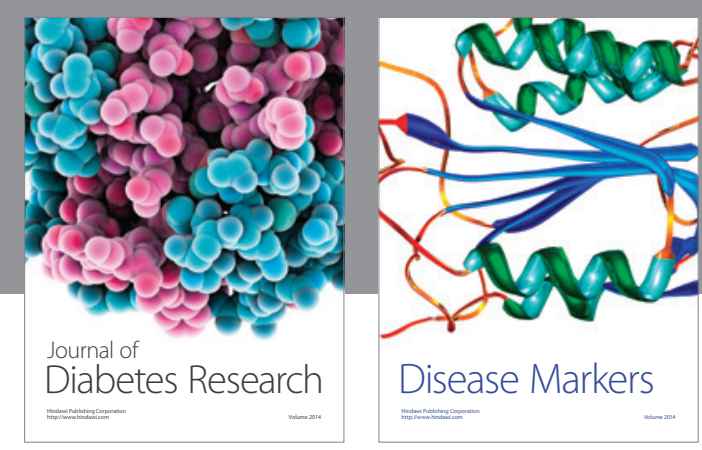

Disease Markers
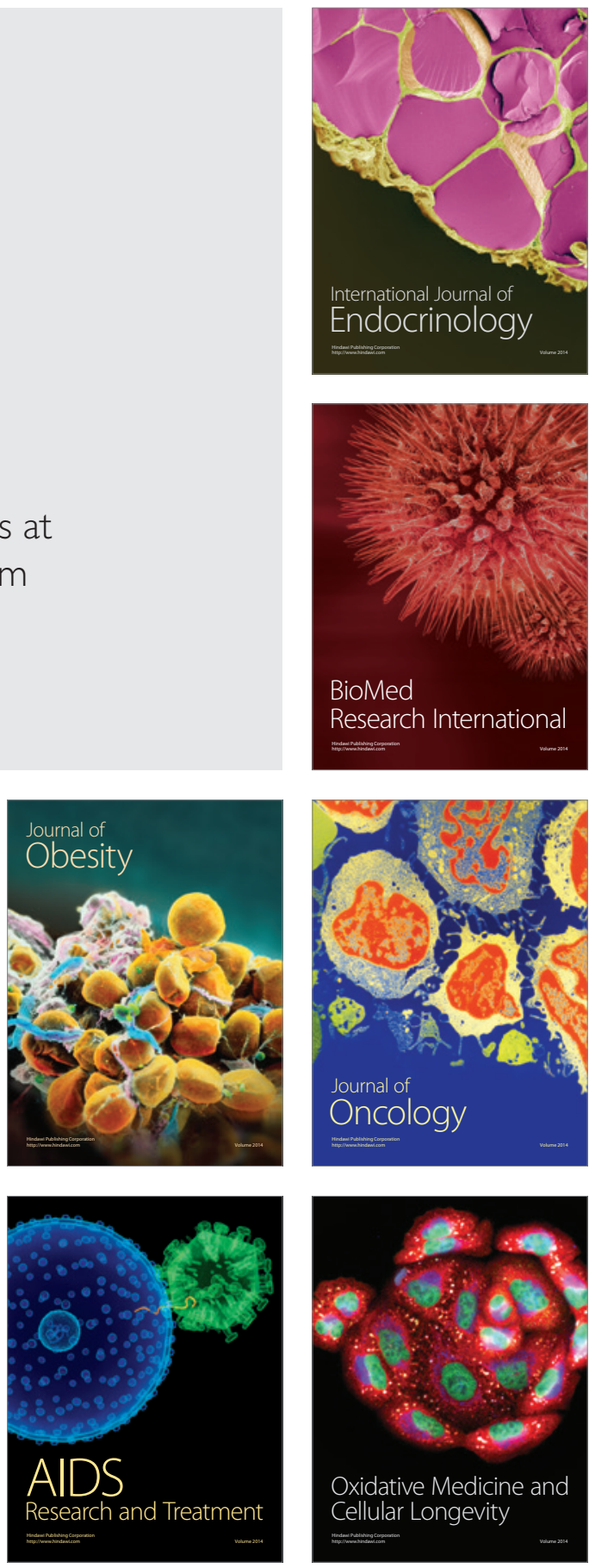